\title{
Late Blood Pressure Reduction in SHR Subjected to Transient Captopril Treatment in Youth: Possible Mechanisms
}

\author{
J. ZICHA, Z. DOBEŠOVÁ, J. KUNEŠ \\ Cardiovascular Research Center, and Institute of Physiology, Academy of Sciences of the Czech \\ Republic, Prague, Czech Republic
}

Received May 2, 2008

Accepted May 21, 2005

\begin{abstract}
Summary
Spontaneously hypertensive rats (SHR) are characterized by enhanced nifedipine-sensitive component of sympathetic vasoconstriction. Our study tried to elucidate the mechanisms responsible for long-term reduction of blood pressure (BP) in SHR subjected to early transient captopril treatment. Adult untreated SHR aged 30-34 weeks were compared with animals subjected to chronic captopril treatment for 6 weeks either in youth (between 4 and 10 weeks of age) or in adulthood (between 24 and 30 weeks of age). Antihypertensive effects of captopril were more pronounced in young than adult SHR. This was due to greater attenuation of sympathetic and nifedipine-sensitive BP components and prevention of residual BP rise in young captopril-treated SHR in which the reductions of nifedipinesensitive BP component and residual BP persisted for 20 weeks after captopril withdrawal. The magnitude of nifedipine-sensitive component of sympathetic vasoconstriction is decisive for BP maintenance not only in untreated SHR but also in SHR during active captopril treatment by or after its withdrawal.
\end{abstract}

\section{Key words}

Genetic hypertension $\bullet$ Late effects of early treatment $\bullet$ Captopril - Nifedipine

\section{Corresponding author}

Josef Zicha, Institute of Physiology AS CR, v.v.i., Videnska 1083, 14220 Prague 4, Czech Republic. E-mail: zicha@biomed.cas.cz

Spontaneously hypertensive rats (SHR) are characterized by sympathetic hyperactivity (Head 1989, De Champlain 1990) that is associated with enhanced contribution of nifedipine-sensitive vasoconstriction to BP maintenance (Paulis et al. 2007). It seems that this alteration is caused by increased stimulation of alpha- adrenergic receptors because norepinephrine (NE) activates L-type voltage-dependent $\mathrm{Ca}^{2+}$ channels (VDCC) in vascular smooth muscle (Nelson et al. 1988).

The mechanisms of BP reduction induced by chronic blockade of renin-angiotensin system also involve a considerable reduction of sympathetic vasoconstriction (Berecek et al. 1987, Hojná et al. 2007, Paulis et al. 2007). Our earlier studies on salt hypertension (Zicha et al. 2001, Dobešová et al. 2002) revealed that sympathetic hyperactivity was more pronounced in salt-sensitive Dahl rats, which were exposed to high salt intake since weaning, than in those influenced by the same hypertensive stimulus only in adulthood. It is well known that the antihypertensive treatment is generally more efficient if applied in young prehypertensive rats (prevention of hypertension development) than in animals with established hypertension (therapy of hypertension) (for review see Zicha and Kuneš 1999). Moreover, antihypertensive treatment of young but not adult SHR with angiotensinconverting enzyme (ACE) inhibitors or $\mathrm{AT}_{1}$ receptor blockers usually causes profound BP reduction which partially persists for a long time after drug withdrawal (Harrap et al. 1990, Adams et al. 1990, Morton et al. 1992), but the mechanisms responsible for this long-term $\mathrm{BP}$ reduction are not completely understood yet.

Our study was aimed to reveal possible mechanisms of long-term BP reduction persisting after the withdrawal of captopril treatment in young SHR and to determine the contribution of changes in sympathetic and nifedipine-sensitive BP components induced by early or late transient captopril treatment. 
Table 1. Blood pressure and its particular components in untreated SHR (aged 30-34 weeks) and age-matched SHR treated for 6 eeks with captopril (100 mg/kg b.w./day) in youth or adulthood.

\begin{tabular}{|c|c|c|c|}
\hline $\begin{array}{l}\text { Captopril treatment } \\
\text { At the age of } \\
\text { Drug withdrawal for }\end{array}$ & $\begin{array}{c}\text { Untreated } \\
- \\
(n=8)\end{array}$ & $\begin{array}{l}\text { Young group } \\
6 \text { weeks } \\
\text { 4-10 weeks } \\
20 \text { weeks } \\
(n=6)\end{array}$ & $\begin{array}{l}\text { Adult group } \\
6 \text { weeks } \\
\text { 24-30 weeks } \\
4 \text { weeks } \\
(n=6)\end{array}$ \\
\hline Mean arterial pressure ( $\mathrm{mm} \mathrm{Hg}$ ) & $203 \pm 5$ & $167 \pm 4 * *$ & $184 \pm 4 * \#$ \\
\hline$\Delta M A P_{\text {captopril }}(m m H g)$ & $-21 \pm 6$ & $-4 \pm 2 *$ & $-6 \pm 2$ \\
\hline$\triangle M A P_{\text {pentolinium }}(\mathrm{mm} \mathrm{Hg})$ & $-89 \pm 4$ & $-78 \pm 4$ & $-92 \pm 3^{\#}$ \\
\hline$\triangle M A P_{L-N A M E}(m m ~ H g)$ & $96 \pm 6$ & $99 \pm 6$ & $80 \pm 7$ \\
\hline Vasodilator deficit ( $\mathrm{mm} \mathrm{Hg}$ ) & $-19 \pm 5$ & $-23 \pm 4$ & $-21 \pm 3$ \\
\hline Residual MAP (mm Hg) & $79 \pm 3$ & $66 \pm 2 * *$ & $64 \pm 2 * *$ \\
\hline$\triangle M A P_{\text {nifedipine }}(\mathrm{mm} \mathrm{Hg})^{\S}$ & $-82 \pm 4$ & $-58 \pm 5 * *$ & $-68 \pm 7$ \\
\hline
\end{tabular}

Data are means \pm SEM. $\S$ - additional group of animals with similar basal mean arterial pressure. Significantly different: $*$, $* *$ from untreated SHR $(p<0.05, p<0.01) ;{ }^{*}$ from young SHR $(p<0.05)$.

The experiments were carried out in 40 male SHR aged 30-34 weeks. Half of the rats were subjected to consecutive blockade of vasoactive systems, whereas remaining animals were used for acute VDCC blockade by nifedipine. We compared untreated SHR with SHR treated with captopril $(100 \mathrm{mg} / \mathrm{kg} /$ day $)$ for 6 weeks starting at the age of either 4 weeks (young group) or 24 weeks (adult group). Thus SHR treated with captopril in youth (4th -10 th week of age) were examined 20 weeks after drug withdrawal, whereas those treated in adulthood were studied 4 weeks after drug withdrawal.

SHR from our own colony were housed under standard conditions (temperature $23 \pm 1{ }^{\circ} \mathrm{C}, 12$-h light-dark cycle, pelleted ST-1 diet with $1 \% \mathrm{NaCl}$ ) and drank tap water ad libitum. The experimental protocol, which was approved by the Ethical Committee of the Institute of Physiology AS CR, conformed to European Convention on Animal Protection.

One day before BP determination, polyethylene catheters were inserted into the left carotid artery and jugular vein and exteriorized in the interscapular region. BP was recorded in conscious rats after 24-h recovery using PowerLab system (ADInstruments Ltd, Bella Vista, NSW, Australia). To eliminate the influence of circadian $\mathrm{BP}$ variation, the measurements were always done between 08:00 and 12:00 h a.m. Baseline values of systolic, diastolic and mean arterial blood pressures were monitored in conscious animals for $30 \mathrm{~min}$. Thereafter a consecutive blockade of renin-angiotensin system (RAS), sympathetic nervous system (SNS) and NO-synthase (NOS) was performed as described previously (Zicha et al. 2001, Hojná et al. 2007). Firstly, intravenous bolus of captopril (10 mg/kg b.w.) was injected to block ACE. Ten minutes later, ganglionic blockade was induced by pentolinium (Sigma, St. Louis, USA, $5 \mathrm{mg} / \mathrm{kg}$ b.w.), which caused rapid BP fall. After the temporary BP stabilization for about $5 \mathrm{~min}$, NOS inhibitor L-NAME (30 mg/kg b.w.) was given and BP restoration was monitored for next 20 min. At the end of the experiment sodium nitroprusside (SNP, $20 \mu \mathrm{g} / \mathrm{kg}$ b.w.) was injected to determine minimal (residual) BP, which reflects structural changes of resistance vessels. The magnitude of vasodilator deficit was estimated from a comparison of BP level reached after SNP injection with that found after pentolinium administration. All drugs (Sigma, St. Louis, USA) were given as an intravenous bolus in a volume of $1 \mathrm{ml} / \mathrm{kg}$ b.w.

BP response to acute VDCC blockade by nifedipine was determined in separate subgroups of untreated and captopril-treated SHR. After monitoring baseline BP for $30 \mathrm{~min}$, increasing doses of nifedipine (Sigma, St. Louis, USA, 0.05, 0.1, 0.2 and $0.4 \mathrm{mg} / \mathrm{kg}$ b.w., dissolved in $50 \%$ ethanol, i.v. bolus $0.2 \mathrm{ml} / \mathrm{kg}$ b.w.) were injected in 10-min intervals. Relatively sharp BP decrease occurring after nifedipine administration was followed by BP stabilization, which was maintained for next $10 \mathrm{~min}$. Stabilized BP values were used for the calculation of nifedipine-induced BP reduction. Results were expressed as means \pm SEM. The data were evaluated by means of one-way analysis of variance with LSD post-hoc test. $\mathrm{P}<0.05$ value was taken as significant. 

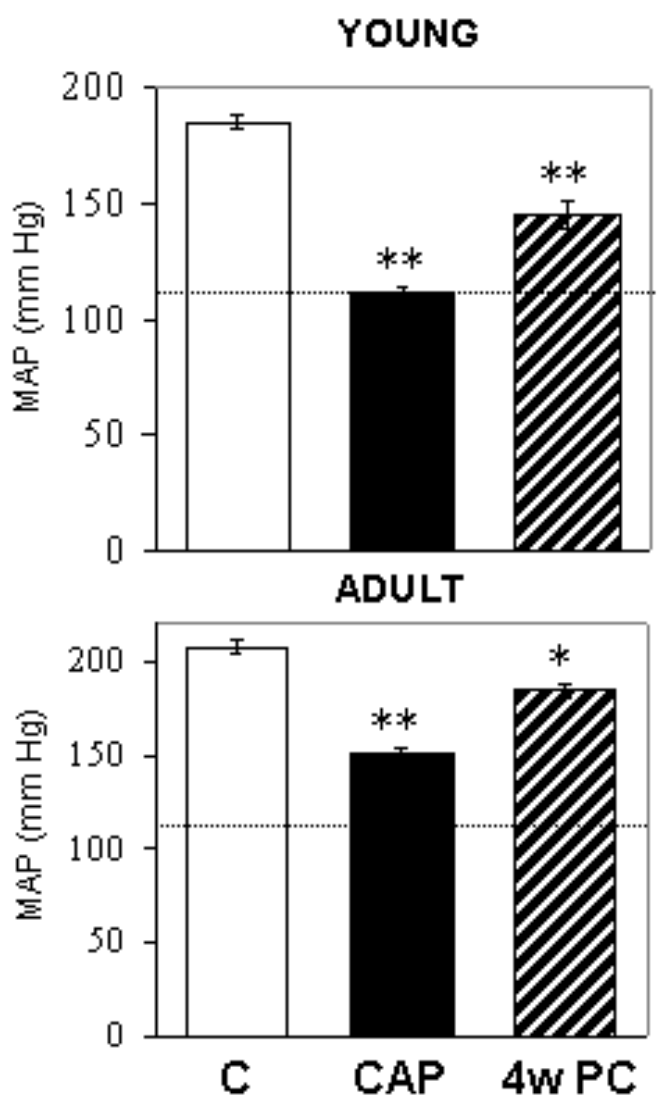

Fig. 1. Mean arterial pressure (MAP) in young SHR (aged 1014 weeks; Paulis et al. 2007) and adult SHR (aged 30-34 weeks; Hojná et al. 2007) - untreated rats (C, open bars), rats treated with captopril for 6 weeks (CAP, full bars) and rats studied 4 weeks after drug withdrawal ( 4 w PC, hatched bars). Dotted line indicates MAP level in normotensive WKY rats.

Early captopril treatment prevented the development of spontaneous hypertension in SHR, maintaining their BP at the level of normotensive WistarKyoto (WKY) rats. Withdrawal of captopril treatment for 4 weeks was accompanied by a moderate increase of blood pressure (Fig. 1), but significant BP lowering persisted at least 20 weeks after treatment withdrawal (Table 1). On the other hand, the same antihypertensive treatment of adult SHR with established hypertension decreased their BP only moderately and BP rose rapidly during 4 weeks after captopril withdrawal (Fig. 1).

Early transient captopril treatment (from the 4th to the 10th week of age) induced considerable changes in the development of hypertension that can de disclosed even after 20 weeks of drug withdrawal (Table 1). BP was decreased by $20 \%$ compared to untreated 30 -week-old SHR due to borderline reductions in angiotensin IIdependent and sympathetic BP components. There was a considerable attenuation (30\%) of nifedipine-sensitive BP fall in captopril-treated group. Both groups did not differ in NO-dependent vasodilation or vasodilator deficit. Residual BP was decreased by $16 \%$ following early transient captopril treatment (Table 1). We can thus compare SHR subjected to transient captopril treatment in youth (studied after 20 weeks of drug withdrawal) with animals subjected to the same treatment in adulthood (studied after 4 weeks of drug withdrawal). It is evident that BP in the adult group (after a short-term drug withdrawal) was less attenuated than BP of the young group after a long-term drug withdrawal. Sympathetic vasoconstriction tended to be greater in the adult than in the young group. In addition, nifedipine-sensitive BP component was not significantly reduced in the adult group in contrast to its major reduction in the young group. Surprisingly, residual BP was lowered to the same extent in young and adult groups (Table 1).

The most important finding of our study concerns the hemodynamic changes responsible for long-term (20week lasting) BP lowering after the withdrawal of captopril treatment of young SHR. We have observed that BP of 30week-old SHR, which were subjected to a transient captopril treatment at the age of 4-10 weeks, was reduced by $20 \%$ compared to untreated age-matched SHR. This $\mathrm{BP}$ decrease reflects a major reduction of nifedipinesensitive BP component and a moderate lowering of residual BP. These two changes seem to represent the alterations induced by early captopril treatment, which persisted for a long time after drug withdrawal. As we already mentioned (Paulis et al. 2007), early captopril treatment of young SHR abolished the rise of residual BP, which is reflecting structural remodeling and/or basal tone of resistance vasculature. After drug withdrawal the value of residual BP did not surpass its level in age-matched control WKY rats. On the contrary, residual BP values decreased by chronic captopril treatment of adult SHR were still considerably elevated as compared to values found in age-matched WKY rats (Hojná et al. 2007). The same was also true for residual BP values found in adult SHR after captopril withdrawal, which was not accompanied by any significant changes of residual BP compared to active treatment period.

Long-term attenuation of BP after transient RAS inhibition in young SHR is in a good agreement with earlier studies (Harrap et al. 1990, Kost et al. 1995, Baumann et al. 2007) which also indicated significant improvement of structural remodeling of cardiovascular apparatus (Christensen et al. 1989, Adams et al. 1990, Morton et al. 1992) and attenuation of end-organ damage (Bergström et al. 2002). However, this study represents a 
rare attempt to evaluate the mechanisms of this $\mathrm{BP}$ reduction on the basis of altered contribution of particular vasoactive systems and/or changes in residual BP (reflecting the remodeling of resistance vessels).

In conclusions, the magnitude of nifedipinesensitive component of sympathetic vasoconstriction is decisive for BP level in SHR, including rats subjected to active antihypertensive treatment or its withdrawal.

\section{Conflict of Interest}

There is no conflict of interest.

\section{Acknowledgements}

This work was supported by grants AV0Z 50110509 and 1 M0510 (Ministry of Education of the Czech Republic) and by research grant of GA CR 305/08/0139.

\section{References}

ADAMS MA, BOBIK A, KORNER PI: Enalapril can prevent vascular amplifier development in spontaneously hypertensive rats. Hypertension 16: 252-260, 1990.

BAUMANN M, JANSSEN BJA, HERMANS JJR, PEUTZ-KOOTSTRA C, WITZKE O, SMITS JFM, STRUIJKERBOUDIER HAJ: Transient $\mathrm{AT}_{1}$ receptor-inhibition in prehypertensive spontaneously hypertensive rats results in maintained cardiac protection until advanced age. J Hypertens 25: 207-215, 2007.

BERECEK KH, KIRK KA, NAGAHAMA S, OPARIL S: Sympathetic function in spontaneously hypertensive rats after chronic administration of captopril. Am J Physiol 252: H796-H806, 1987.

BERGSTRÖM G, JOHANSSON I, WICKMAN A, GAN L, THORUP C: Brief losartan treatment in young spontaneously hypertensive rats abates long-term blood pressure elevation by effects on renal vasculature. J Hypertens 20: 1413-1421, 2002.

CHRISTENSEN KL, JESPERSEN LT, MULVANY MJ: Development of blood pressure in spontaneously hypertensive rats after withdrawal of long-term treatment related to vascular structure. J Hypertens 7: 83-90, 1989.

DE CHAMPLAIN J: Pre- and postsynaptic adrenergic dysfunctions in hypertension. J Hypertens 8 (Suppl 7): S77-S85, 1990.

DOBEŠOVÁ Z, KUNEŠ J, ZICHA J: The altered balance between sympathetic nervous system and nitric oxide in salt hypertensive Dahl rats: ontogenetic and $\mathrm{F}_{2}$ hybrid studies. J Hypertens 20: 945-955, 2002.

HARRAP SB, VAN DER MERWE WM, GRIFFIN SA, MACPHERSON F, Lever AF: Brief angiotensin converting enzyme inhibitor treatment in young spontaneously hypertensive rats reduces blood pressure long-term. Hypertension 16: 603-614, 1990.

HEAD RJ: Hypernoradrenergic innervation: its relationship to functional and hyperplastic changes in the vasculature of the spontaneously hypertensive rat. Blood Vessels 26: 1-20, 1989.

HOJNÁ S, KADLECOVÁ M, DOBEŠOVÁ Z, VALOUŠKOVÁ V, ZICHA J, KUNEŠ J: The participation of brain NO synthase in blood pressure control of adult spontaneously hypertensive rats. Mol Cell Biochem 297: 21-29, 2007.

KOST CK JR, LI P, JACKSON EK: Blood pressure after captopril withdrawal from spontaneously hypertensive rats. Hypertension 25: 82-87, 1995.

MORTON JJ, BEATIE EC, MACPHERSON F: Angiotensin II receptor antagonist losartan has persistent effects on blood pressure in the young spontaneously hypertensive rats: lack of relation to vascular structure. J Vasc Res 29: 264-269, 1992.

NELSON MT, STANDEN MB, BRAYDEN JE, WORLEZ JF: Noradrenaline contracts arteries by activating voltagedependent calcium channels. Nature 336: 382-385, 1988.

PAULIS L, LÍŠKOVÁ S, PINTÉROVÁ M, DOBEŠOVÁ Z, KUNEŠ J, ZICHA J: Nifedipine-sensitive noradrenergic vasoconstriction is enhanced in spontaneously hypertensive rats: the influence of chronic captopril treatment. Acta Physiol (Oxford) 191: 255-266, 2007.

ZICHA J, KUNEŠ J: Ontogenetic aspects of hypertension development: analysis in the rat. Physiol Rev 79: 1227-1282, 1999.

ZICHA J, DOBEŠOVÁ Z, KUNEŠ J: Relative deficiency of nitric oxide-dependent vasodilation in salt hypertensive Dahl rats: the possible role of superoxide anions. J Hypertens 19: 247-254, 2001. 